\title{
Social News Use \& Citizen Participation among Young Activists in Singapore
}

\author{
Winston Teo \\ https:// orcid.org/0000-0002-1939-8376 \\ School of Social Sciences, University of Auckland, New Zealand, w.teo@auckland.ac.nz
}

\begin{abstract}
This article presents a study of how civically engaged young adults engage with news on social media, within the context of a developing democracy - Singapore. Based on in-depth interviews with 20 young activists, it discusses how they approach social media as a source of news, what motivates them to engage in more than one social news platform, and how social news use fits into their political lexicon. The results reveal that despite their affinity towards news-related content on social media, they are neither partial towards mainstream, nor alternative news providers on this medium. Their primary social news platform is perceived to offer the best means to disseminate news-related information. However, they are also concerned about their privacy and practice certain strategies to mitigate this. Despite its drawbacks, the activists accept social news use as a viable means of political socialisation and mobilisation.
\end{abstract}

Keywords: social media, social news, citizen participation, young adults, Singapore

\section{Introduction}

The pervasiveness of social news use - the use of social media for news-related activities - particularly among adolescents and young adults, is well-documented (e.g. Marchi, 2012; Sveningsson, 2015). Surveys from Reuters Institute for the Study of Journalism found that while Facebook remains currently, the most popular social media platform for news use (36\%), the instant-messaging and microblogging applications WhatsApp and YouTube are its closest competitors worldwide (Newman et al., 2019). Overall, $16 \%$ of its sample, consume, share or discuss news through WhatsApp and $10 \%$ of them use YouTube in a similar fashion. Research has indicated that those who regularly engage in such activities on social media are driven by the need to not just keep up to date with current affairs, but also to broaden one's perspectives beyond mainstream views (Hermida et al., 2012; Sveningsson, 2015). Indeed, social media is arguably a purveyor of alternative news because the owners of such enterprises often lack the economic resources needed to create, package, and distribute content widely through traditional means (e.g. broadcast). In developing democracies where traditional news media is still highly structured and regulated by the state, social media is more crucial in providing access to this resource. 
However, despite the rising popularity of social news use, extant research in communications have often focused on two main areas: antecedents (e.g. Bergström \& Belfrage, 2018; Choi, 2016; Glynn et al., 2012; Lee \& Ma, 2011; Shearer \& Matsa, 2018), and effects (Bachmann \& Gil de Zúñiga, 2013; Kim et al., 2013; Park \& Kaye, 2019; Saldaña et al., 2015; Yamamoto \& Morey, 2019). Scholarly work in the former tend to employ a quantitative approach, examining for instance, the influence of motives, life satisfaction, media repertoire, age, and the presence of opinion leaders. The varied ways in which social news users engage with news on different social media platforms and why, has received significantly less scholarly attention. Granted that social media is a host to both mainstream and alternative news content, it is necessary to further understand how users adopt their news consumption behaviours to this diverse media landscape. Similarly, while the positive outcomes of social news use on civic/political life has been explored on several occasions, fewer researchers have also considered how this relationship can also be undermined.

To fill the gap in literature, the current study examined how social news users engage with social media news content from two angles: 1) sources (mainstream / alternative news providers) and 2) platforms (e.g. Facebook, WhatsApp, etc), using qualitative data gathered from in-depth interviews with young adult activists in Singapore. Building on preceding qualitative studies, this research does not focus on a particular social news use activity - i.e. consumption or sharing. It also explores if activists utilise more than one social news platform and if so, how much does information control, or their perceived efficacy to effectively utilise the features of the medium, influence this. This comparative work will help us to understand the use of one type of social news platform in relation to another and further elucidate why users are reliant on more than one platform (Newman et al., 2019). In addition, this paper also examined how such activities present both opportunities and challenges for citizen participation. Focusing on activists is apt as previous research has often corroborated on the link between news use and an active citizenry (Kang \& Kwak, 2003; Mcleod et al., 1999). This study also adds to the body of research outside of a North American or European context. Singapore is a technologically advanced city-state and its residents are among Asia's most prolific social media users (Kemp, 2020), with $79 \%$ of the total population using at least one social media platform regularly. Unsurprisingly, online and social media have also become an integral gateway to news (Newman et al., 2019). However, it is also a society often characterised as politically apathetic - with opposition parties and civil society organisations only becoming more active at the turn of the century (George et al., 2014). Singapore thus represents an interesting case study for how people engage in social news use and the implications this has on citizen participation.

\section{News on social media in Singapore}

Singapore is identified as a flawed democracy (Economist Intelligence Unit, 2019), where while parliamentary elections are held periodically, free of irregularities and fraud, the ruling party has not experienced any real challenge towards its hegemonic domination since independence. The absence of a turnover in government and dearth in competitive party politics has been attributed to a slate of electioneering and punitive legislative devices (Welsh, 2016). As a critical part of political control, mainstream news media in Singapore operates in an environment closely structured and controlled by the state, and is thus partial towards the political status quo through more positive 
and greater coverage (Cenite et al., 2008). Interestingly however, regulations concerning new media are dispensed with a "lighter touch" (George \& Raman, 2008). Notwithstanding a mandatory licensing regime (IMDA, 2017), wholly independent news sites and politically oriented social media pages are permitted to exist and adopt a political or oppositional watchdog role. Consequently, a number of alternative news content providers has mushroomed in the last decade, providing perspectives beyond the otherwise closed media system in Singapore.

However, as pointed out by Hermida (2011), because social media has allowed any user to post, reshare or copy content easily, it has disrupted the news production and diffusion process previously dominated by traditional news outlets. News content disseminated through these means do not necessarily conform to the traditional practices of professional journalism such as formal factchecking procedures. Indeed, personal discretion and accountability are the only mechanisms that guard the quality of information individuals share. Extant research has demonstrated support for this proposition. A qualitative study by Marchi (2012) found that North American adolescents were more inclined towards informal news sources such as social media because they found it more opinionated. Similarly, many of the focus group participants in Sveningsson's study (2015) raised the issue of subjectivity and uncertainty in social media news. In the context of Singapore, it was reported that while digital media, such as social media, has become a popular news source, more than half of adolescents and young adults have been misinformed through such means $(\mathrm{Ng}, 2018)$. Put together, the literature suggests that on one hand, news on social media provides its consumers with the opportunities to expand their perspectives on politics and social issues, beyond mainstream views; however, on the other hand, the veracity of the information shared in these spaces, particularly those provided by alternative news providers, might be suspect. Therefore, the following research question is raised:

RQ 1: How do civically or politically engaged millennials make sense of social news disseminated by both mainstream and alternative news providers?

\section{Self-presentation and information control}

Goffman (1959) has suggested that individuals are inclined to engage in self-presentation processes to gain social rewards or avoid social stigmas. This impression-management behaviour can be categorised into two primary actions of information control: 1) revealing or highlighting desirable aspects of one's own identity and 2) concealing potentially stigmatizing information. More recently, Feaster (2010) framed information control as a media affordance - expressive and private - taking into consideration one's perceived efficacy to effectively utilise the features of the medium to express or withhold information as required. Accordingly, Feaster's research (2010) discovered that the more expressive information control was reported for a communication medium (e.g. IM, email), the more likely individuals would select it in face-threatening situations. A subsequent study has confirmed the value of this finding; in 2013, Kuo et al. (2013), demonstrated that both expressive and privacy information control perceived on Social Networking Sites (SNSs) positively influenced its usage. A possible explanation for this is that affordances featured on social media arguably present greater opportunities for self-expression than Face-to-Face (FtF) interactions (Walther et al., 2015). Unlike in the latter, social media users have a greater capacity to reveal, omit, or regulate information about 
themselves in an ideal and intended manner. Indeed, while individuals can attempt to make salient certain aspects of themselves in FtF interactions, they are disadvantaged as they have to dedicate additional cognitive resources to monitor non-verbal expressions or effects of response latencies.

However, it has also been pointed out that while the characteristics of social media platforms have given individuals the opportunity to interact with large and diverse audiences, the same affordance has resulted in context collapse (Marwick \& boyd, 2011). In contrast to offline settings where individuals can self-present accordingly to diverse audience segments in explicit spatial and temporal contexts, the selves presented on social media are subjected to the surveillance of a heterogeneous network with varying expectations (Marder et al., 2012). Research has shown that to manage diverse audience expectations of appropriate behaviours, individuals have turned to protective self-presentation strategies, such as employing a lowest common denominator (LCD) approach (Hogan, 2010) or self-cleansing (Lang \& Barton, 2015; Smock, 2010). The former refers to restricting communication to information that is acceptable to all members of the network, whereas the latter involves removal of unwanted information linked to an individual's account through means of untagging or deletion.

These studies illustrate that individuals are concerned with impression management online and will leverage on the affordances of the medium to express or restrict information about themselves. It is thus reasonable to study how information control can influence how one engages in social news use. Accordingly, the following research question is proposed:

RQ 2: How does the perceived affordance of information control influence civically or politically engaged millennials social news practices?

\section{Social news use \& citizen participation}

In political science, an early definition of citizen participation was restricted to acts related to electoral activities such as voting or campaigning for a political candidate (Conway, 1985). Since then, a number of scholars have explicated the evolving norms of citizen participation. Bennett (2008) posits that in many post-industrial democracies, there is a progressive shift in citizenship style, with people transiting from "dutiful" citizens to "actualising" citizens. Dutiful Citizens (DC) make an effort to participate in government-sanctioned activities, vote, become more informed about politics and current affairs via the mass media, and generally see government as the site of politics. The older generation, in general, tends to exercise citizenship in terms of duty. Actualising Citizens (AC), on the other hand experience political engagement on a more personal level, preferring instead to chart their own democratic agenda, for instance, through support for causes like environmental or animal rights, local volunteerism, and consumer activism (Bennett, 2005). In contrast to DC, they generally mistrust traditional news media or mainstream news media organisations and get political information from peer-shared information sustained by interactive information technologies. While poignant, it should be acknowledged that Bennett's observations were partial towards full-fledged democracies. Moreover, it is also common now for legacy news media organisations to have an active presence on social technologies. 
Bennett's (2008) AC/DC model is consistent with Dalton's (2008) work on shifting citizenship norms, in which the latter suggests the terms "dutiful" and "engaged" citizens. According to Dalton, there are four dimensions to citizenship: public participation in politics, autonomy generated through access and deliberation of information, commitment to social order, and ethical and moral responsibility to others. He posits that all facets of citizenship norms, not the least of which is public participation, have changed. Conducting factor analysis on survey data, he finds that DC are oriented towards law and order, valuing institutional participation such as voting or serving on a jury, whereas Engaged Citizens (EC) are aligned more towards liberal or communitarian ideals, favouring instead to be politically independent and focused on single issues such as voluntary welfare aid. Building upon these conceptual understandings, this research acknowledges that citizen participatory behaviours can occur in both the political and civil domain. Here, citizen participation or activism is identified as the sustained involvement in influencing government action and policies (Verba et al., 1995) as well as work that is focused on improving conditions at the grassroots level (Zukin et al., 2006).

The role of news in facilitating engagement in public life is well-established; there is a body of research that suggests that social media - social news in particular - can have a positive effect on citizen participation (e.g. Kümpel, 2020; Kwon et al., 2021; Nah et al., 2021; Yamamoto \& Morey, 2019). Unlike with traditional mass media, social media arguably brings more opportunities for mobilization because they allow those who are inactive or marginalised from the current political system to be informed incidentally of civic and political opportunities. Incidental exposure to news on social media is notably higher than through other channels due to its potential for scalability (boyd, 2010). The platforms support the sharing and receiving of content from beyond one's immediate network, thus increasing one's chances of encountering news items while using the site for other purposes. Furthermore, the various interactive features of social media such as comment threads foster further reflection and efficacious feelings about matters of public concern and in turn are likely to motivate participation in these issues (Gill \& Rojas, 2021).

However, some scholars have cautioned against drawing firm conclusions about the mobilizing potential of digital technologies, arguing that that such expectation is largely applicable to those who are already politically engaged (Kluver, 2004; Norris, 2001). This perspective, otherwise known as the reinforcement hypothesis, traditionally holds the assumption that because only privileged groups have the means to leverage on these technological resources, current participatory inequalities will not be reduced or changed (Tai et al., 2020). It should be noted that Singapore has a highly developed information infrastructure with 98\% connectivity (IMDA, 2018) so the merit of this argument is limited. Nonetheless, despite the pervasiveness of social news use among the populace, there are reasons to believe that engaging in such activities may not be beneficial for civic and political life. Wohn \& Bowe (2016) have noted that the internet, and more lately, social media, facilitate selective exposure and ultimately leads to the creation of echo chambers or filter bubbles - communication spaces that reinforce one's views and ideas. In a study examining the sharing behaviour of more than 10 million Facebook users, Bakshy et al. (2015) demonstrated that users are more likely to encounter news and information consistent with their political dispositions. This is partly attributed to the network's algorithm of recommending new preferable items based on previous use and to users themselves who are unlikely to share cross-cutting content with others. 
Other scholars have also cautioned against slacktivism (Cabrera et al., 2017; Chen et al., 2018). The critique is that online political activities - including social news use - are low-risk non-committal practices that are not sufficient in themselves to encourage real-world citizen participation. Rather, they serve primarily to grant the satisfaction of being involved. Moreover, social media may not be well-suited for meaningful discourses about politics and public affairs because it is used for a myriad of purposes. Not all who encounter such information will choose to engage with it fruitfully, if at all. As an informant in Skoric \& Poor's study (2013) on young activists pointed out, "I don't think Facebook is a quality comment thing. People go there just for fun." Guided by these competing lines of reasoning and empirical findings, this study thus asks the following question:

RQ 3: How does social news use facilitate or inhibit citizen participation?

\section{Methodology}

A purposive and snow-balling sampling method was used to recruit interviewees. The initial call for participants was first emailed to organisations of the following three communities: 1) welfare organisation groups, 2) single-issue movements, 3) political parties. The first category refers to communities involved in philanthropy work such as free assistance to old and needy individuals, the second refers to groups that are involved in a specific cause such as gender equality, and the latter groups are those whom are involved in party politics. Recipients were requested to forward it within their personal networks. To qualify, participants had to be between the ages of 21-35 years old, to be current members or volunteers of either of the above-mentioned three communities and have been involved with them for at least a year. The interviews were part of a broader $\mathrm{PhD}$ project that investigated the respondents' level of interaction and their involvement in the political process and as such, the decision to limit the inclusion criteria to millennials of voting age.

Prior to the interview, respondents were provided with an information sheet to read and a consent form to sign. In addition, they were reminded that their participation would be voluntary and anonymous. Hence, while names of the individuals and their communities were recorded in this research, they will not be presented in this paper. Instead, the respondents were assigned letter labels (A-V) and their communities were identified broadly, such as "human rights group". Following their consent, informants were asked to fill in a short questionnaire (Appendix A). The survey form is designed so as to collect some demographic and other basic information on interviewees' existing social news use behaviours and motivations. Consistent with earlier studies, news consumption included traditional mass media sources (i.e. television, radio, and newspaper) and digital sources (i.e. social media, internet). Participants were also asked to rank how frequent they utilized the different social media platforms for news.

The qualitative in-depth individual interviews were conducted between October 2017 and February 2018. They had a semi-structured character and were based on 10 open-ended questions (Appendix B). Each was conducted face-to-face at a time and place convenient to the interviewees and took about an hour to two hours to complete. Some of the interviews were conducted in the participants' homes and others were in public spaces, such as cafes. All interviews were audio recorded (with the interviewees' permission) and transcribed by the researcher. The transcripts were 
then uploaded to the qualitative data analysis program NVivo and analysed in three steps. Descriptive coding was employed in the first round (Saldana, 2015). Specifically, the researcher read the interview transcripts several times and coded them line-by-line, only describing the topical contents (e.g. "mainstream news", "alternative news"). A matrix organised by these codes was then created and themes were identified by combining and comparing them. Finally, the themes were organised under the research questions as discussed above.

A total of 20 interviews were conducted, with an average age of 27, 11 of whom were female. An effort was made to ensure racial minorities were represented as well (13 Chinese, 4 Malays, 2 Indians, and 1 "Other"). The sample showed an average of 15 years of formal education in Singapore, which is equivalent to an undergraduate degree. The interviewees reported that they were somewhat, or very, interested in local politics or social issues $(M=4.45$ on 5 -point scale). In the same vein, they paid close or very close attention, to news concerning these issues $(M=3.9$ on a 5-point scale) and somewhat agreed or disagreed, that people like themselves could influence the government ( $M=4.65$ on a 7-point scale). They also reported discussing current affairs with others once a day. These figures indicate that the sample was indeed not representative of the general youth population, but rather, of more active members of society. Moreover, the sample was also a social news use experienced group - they had an average 8-year history of engaging with news on social media several times a day. Conversely, they only consume news on more traditional channels, such as radio and television, once a week on average. This suggests that the sample is a group of young adults well-socialised with the digital news media landscape.

\section{Results}

\subsection{RQ 1: How do civically or politically engaged millennials make sense of social news disseminated by both mainstream and alternative news providers?}

When it comes to staying informed on local issues, all but two of the respondents did not consume exclusively from mainstream or alternative sources online. Part of this stems from a certain level of media scepticism, or " a subject feeling of mistrust toward(s) the mainstream news media" (Tsfati \& Cappella, 2003, p. 506):

So when I see a post by the The Straits Times, I know I'm going to approach it with a truck load of salt because I know what they did before and I know their intentions. But like I said, sometimes I get pleasantly surprised at the accuracy of the article. (Q., a political party member).

I consume mainstream media, but I tend to look at it with more scepticism. Just because I've learnt to be sceptical with mainstream news media outlets. Especially when it comes from Singapore. Because it's controlled by the government and stuff like that. (K., a gender equality rights activist).

I do follow mainstream media actually, but my issue is not so much that they straight out lie. It's lying by omission. (F., a human rights activist) 
However, at the same time, it is also inaccurate to suggest that this means that they are, by default, partial to alternative media sources as well. K. later noted, “...to an extent, I also do regard them (alternative news media) with scepticism because it maybe hearsay". Similarly, Q. and F. added respectively:

I don't like things like All Singapore Stuff, where they post a lot of click-bait articles. I think that is completely lacking in terms of journalistic integrity. What's the other one called? The States Times. Oh my God, the stuff there is just bullshit. They're very anti-government but there's no critical thinking at all.

I was very turned off by The Independent Singapore and they had this tendency of skewing headlines in a way that fed to a specific tribe. So they were always emphasising issues with headlines like this foreigner did this, or this PRC did that. I did not like that sort of editorial judgement.

These instances also suggest these young activists are not passively consuming news but are also evaluating the messages they receive, or are at least wary of sensational, exaggerated or unsubstantiated content. Their experience as news workers or activists who have produced their own media messages helps explain this healthy scepticism. Like many Singaporeans in a recent study $(\mathrm{Ng}$, 2018), they prided on their ability to differentiate between reliable and suspicious news and information sources. In defence of this claim, they pointed out several strategies in identifying potentially non-credible content. One approach, as D., a student activist who focuses on LGBT issues noted, is to trace the credentials of these information producers:

So, The Middle Ground for example, is run by Bertha Hanson, a former news editor, and Daniel Yap, who has had a good career in PR before coming over to journalism and has also been commenting over the internet for years and years. So I trust the people who have been running behind... Must Share News, All Singapore Stuff, Fabrications about the PAP, Fabrications Lead by the Oppositions, all these subpages where the background is shady, you don't know who exactly is running it. Nothing has been tracked. Nothing has been checked. These are the pages that I avoid. These are the pages I don't think are legitimate.

In addition, they also paid attention to how the news or the message is constructed. Many of the interviewees recognised that subjectivity is part and parcel of news making and does not necessarily compromise the legitimacy of the message. Nevertheless, they are likely to doubt the veracity of the information if it is presented in a tabloid-like or over simplified manner. For instance, R., a human rights activist, stressed that one should not just look out for biasness in statements but the depth of coverage when evaluating information:

There are certain criteria of course. Like, what sort of words do they use? What language are they using? And what about their sources, right? So, let's say if The Independent (Singapore) writes something based on a person's Facebook post or a screenshot of a Facebook post. And if we read further down, we find out that they actually did not have any contact with that person. No interviews. Nothing. Then I'll be like, "Is this gossip?"

In the same vein, I., who works on issues related to support and advocacy for sex workers interpreted empty referents in the headlines as a sign of untrustworthiness: 
In fact, recently there was this article posted by Business Times, I think? ...It was a terribly written article. Like a primary school kid wrote that article. The headline was about how pimping was on the rise in Singapore. But the article had no statistics, no trends, no analysis of the situation, and no mention of pimping except in the first sentence.

It should also be noted that none of the respondents consume news (mainstream or otherwise) on social media only. Several interviewees mentioned that they also included news apps or content aggregators in their repertoire. The latter in particular, allows them to verify news pieces efficiently by squaring them off one another on one platform. I. said:

It (Google Alerts) helps me compare headlines. Because in Google Alerts, similar news articles would be combined in a list or there would be a link to another article. So the first one could be The Straits Times, and then they will put, "Also, see this or that related article". Then from there you can clearly compare the news already.

The findings thus far are instructive. Consuming news in the online environment requires discernment and most of the informants are applying various critical thinking strategies. Further, their general sense of ambivalence or unwillingness to rely on a particular media organisation wholly suggests an awareness of the influence of the media. However, as mentioned before, online news use - particularly social news use - differs from accessing other news on other media channels, because it also allows its users to be part of the production or dissemination process as well. The following set of findings looks at how news engagement is influenced by the platform's perceived affordances.

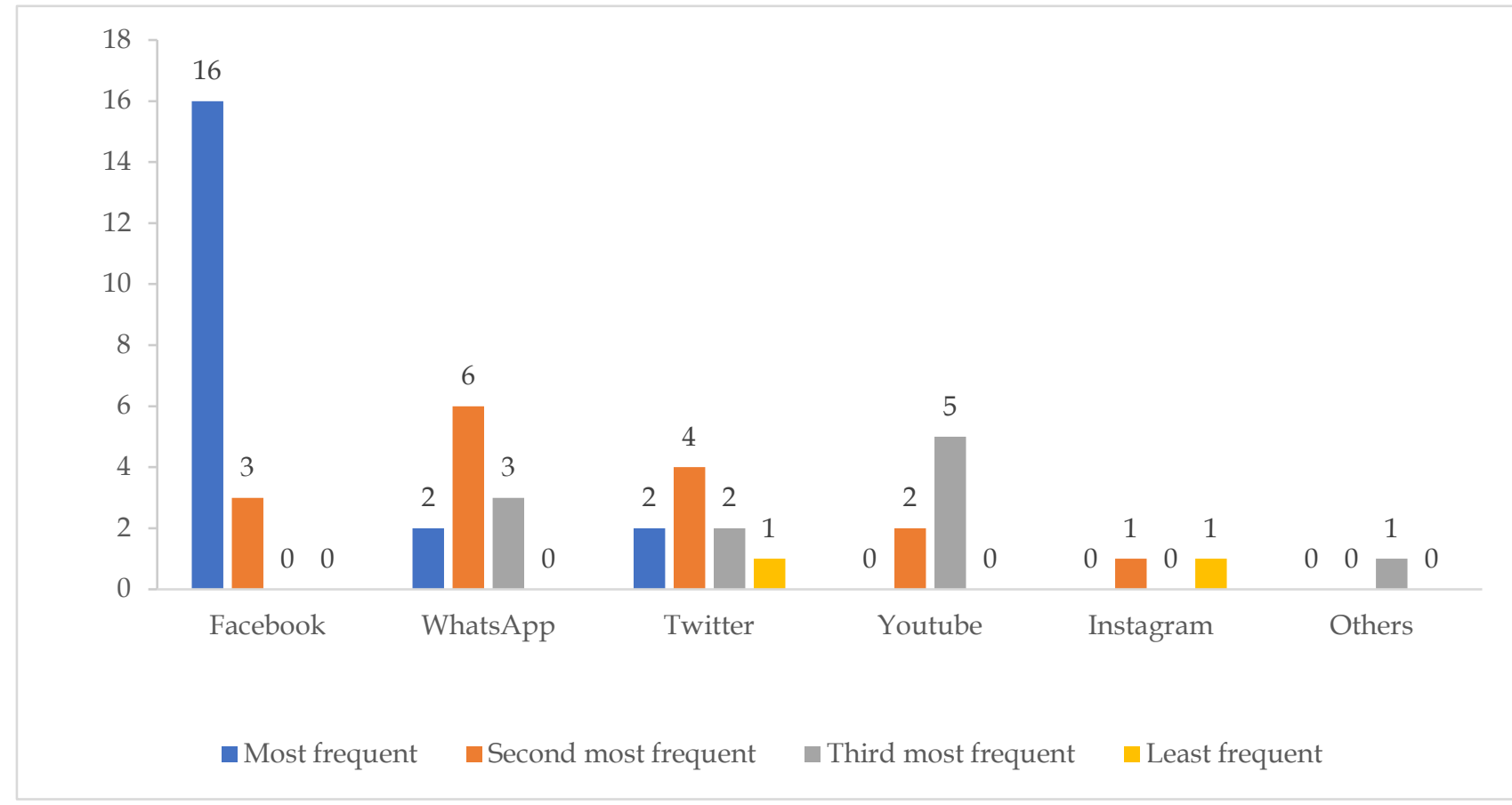

Figure 1: Top social news platform in order of frequency 


\subsection{RQ 2: How does the perceived affordance of information control influence civ- ically or politically engaged millennials' social news practices?}

As shown in Figure 1, Facebook was the primary social media platform for news engagement for most informants. Four participants however, identified either WhatsApp or Twitter as their primary channel. A majority also used a second platform, the most common of which was WhatsApp. Conversely, only about half of them used a third platform and a minority (two) used a fourth platform. When the young activists studied discussed how they engaged with news on different platforms, it became obvious that for most of them, their primary social news platform was also the platform in which they engaged with news more proactively. For instance, A., a human rights activist, disclosed that he runs a Facebook page known to regularly produce content that contests or discredits mainstream views on politics and social issues. However, when asked to explain what he does when engaging with news on WhatsApp, his second most frequently used platform, he responded: 'I use WhatsApp for news in a consumptive way. Usually when there's breaking news or something like that, I will receive it through WhatsApp... like, "Hey this is happening".' In the same vein, M., a minority rights advocacy activist expressed that while she does not (re)produce news content regularly, either as an individual or on behalf of her organisation, it is "comparatively more" than her second platform, YouTube where she has never gone beyond consuming or direct resharing.

Most informants agreed that compared to other platforms, Facebook provided the means to construct richer messages of image and text. Nevertheless, a commonality that emerged from most participants was the perception that their primary social news use platform offered the most efficient means to interact with their target audience. S., a minority rights advocacy activist, pointed out,

If you want people to see something, then Facebook is the most convenient because you're broadcasting to everyone unless you set it otherwise... In WhatsApp you can only forward to a specific group or person unless you broadcast it but then you also have create a list anyway so that is kind of irritating. So, Facebook has the best features for outreach.

Similarly, K. explained how affordances like tweet threads enable her to quickly connect with other interlocutors not in her immediate network:

Specifically, in terms of connectivity through threads. Thread discussions are just something that you can very easily click on and then get linked to another, and another, and another (related tweet). Kind of like jumping posts. Whereas on Facebook, I feel like if you comment on Facebook, it tends to remain on that particular page.

Studies in information control have often focused on "the capacity to control the timing, duration, and nature of information" in a communication environment (O'Sullivan, 2000, p. 412); the above statements suggest that more active social news users will also exploit the technological aspects of the platform to enhance the range of their engagement.

At the same time however, none of the participants rejected the notion of context collapse. The informants explained they had "friends" or followers from diverse networks - family members, colleagues, acquaintances, etc - on their primary social news platform. Unsurprisingly, many participants also articulated their concerns over how the information they share or reproduce can be problematic to some of these contacts. These anticipated relational tensions were based on their own 
experiences or of other users of whom they've witnessed before. P. is a political party volunteer and she said:

I had some friends telling me that I was posting too much things that is very...they call it negative. They told me I always seem to be complaining about the government. And some people don't like it. They might start to unfollow or block you after this. And your relationship with them might become more distant after that.

Overall, the young activists were aware of the potential negative implications of sharing information, particularly with known pre-existing ties. In line with prior research, participants in this study also adopted various practices to prevent the disclosure of certain materials from reaching these unintended recipients. The most common strategy was the utilisation of privacy settings or features inherent in the platform. While they did not often ignore or deny requests from known or unknown others to follow their accounts, they actively managed acquaintance lists or "friend groupings" of whom will have restricted access to their posts by default. Further, several participants also reported using ephemeral features as an added layer of privacy protection. Ephemeral features e.g. Instagram's Story - allow the user to predetermine the expiry of a message/post. To circumvent her parents' surveillance, J. an advocate for LGBT rights, uses Stories on both Facebook and Instagram to relay quick responses to a selected few.

In addition, half of all participants also admitted circumventing concerns over divergent audiences by presenting their political or civic identity - which, uncoincidentally, is also the same facet which is more engaged with news - on one social media platform or account specifically. L., a political party member, and D. both listed Facebook as their primary social news use platform and Instagram as one of their secondary platforms. Respectively, they pointed out:

I use Instagram as way to like, split my 'zen' self away from my political activist self. And the people that are on my Instagram are also slightly different from the people on my Facebook. Actually, quite different. And so on Instagram a lot it is about sharing my yoga journey. Sharing a lot more 'lifestyle' stuff. Occasionally I will put in a photo or two on political matters. But they will be ideological, abstract posts.

I speak about issues that I feel very strongly about. But what I present to the public is a persona. I present a persona of someone who is active in these issues. But I keep a lot of my private life to myself. So my Instagram account is private. I don't post about my relationships on Facebook. I don't post about family on Facebook... make a very active attempt to curate it. So that people will only get that perspective.

Such segregation through multiple accounts allows them to not only leverage on the differences in interactive affordances across platforms, but also reduces the discrepancy between the imagined and the actual audience within these platforms. Arguably, this explains why they engage more actively with news in their primary social news platform and limit engagement to consumption only on their secondary platforms, if adopted at all. 
Although uncommon, a few participants dealt with context collapse with an LCD approach. Users of this strategy often relied on more ambiguous disclosures, as observed in social services agency volunteer E.'s comment: “So, I wouldn't comment anything outright usually. I'll just maybe repost it with '...'." Alternatively, this strategy could also result in the reduction of disclosures altogether. T., a member of an environmental group, said:

I don't think I've ever commented on a public news item. Maybe I have but maybe it was only once. And that's because I like to preserve my privacy. And yea, I suppose I'm too lazy to set up a separate Facebook account.

It should be noted that their tendency to apply the LCD approach does not stem from a lack of awareness in privacy settings, but a general distrust towards other users who might disseminate their posts to unintended recipients. All in all, the young activists were aware that the affordances inherent within social media facilitated message amplification, thus giving them the means to communicate with people whom they could not otherwise reach. At the same time however, they were concerned with their self-presentation, or more specifically, mitigating offense across diverse social groups. Accordingly, many dealt with this issue by adopting and/or manipulating certain features to exclude those deemed unsuitable for specific information. Others who were more critical of the limitations of these technical affordances preferred to use a dedicated platform for news engagement or restrict their news-related activities completely.

\subsection{RQ 3: How does social news use facilitate or inhibit citizen participation?}

Responses from the interviewees showed that both reinforcement and mobilisation hypotheses might be at work, in line with earlier research (Nam, 2012; Vissers \& Stolle, 2014). Half of the informants in this study denied that their trajectory to activism was initiated by news engagement or the internet, although it has facilitated their ongoing civic or political participation. C., a grassroots leader, emphasized that the Internet only expanded the existing modes of interaction with his community, and that he would still be very much involved with or without online media. He said:

I will still be equally invested. Because being involved in grassroots, I'm already part of coordinating messages between government and people, such as through organising dialogue sessions. When social media came around, it gave people like me a lot more work to do because we had to start engaging these spaces. We had to stake our space there and start responding to content. So even if social media didn't come around, I'd continue doing the dialogue sessions, the walk-abouts, and the house visits.

Similarly, L. initially claimed that she was not influenced by the media to be involved in politics or animal welfare activism, but rather, the community with which she surrounded herself with at university. However, she later acknowledged a cycle in her involvement:

... I think it works both ways. Searching and finding about such things online does make more interested in politics. But also, I'm in politics myself so I am keen to be more exposed. And therefore, it makes me more interested. 
On the other hand, some participants indicated that if it weren't for social media, it would have been more unlikely to have been drawn into activism because their opportunity to engage with political news and information would be reduced. P., for example, recalled how her current political involvement was prompted by social news use:

I think my friend shared something from ToC. At that time, I was just curious because it was General Elections that year. So, I learned about this very interesting party that has been saying things that pretty much made sense. Then I started to 'follow' them. Started to share news related to them. Eventually I also went for their rallies.

Likewise, A. claimed that he was recruited into advocating for public causes after interacting with issues related to public affairs on social media. Such accounts ostensibly provide support for the view that the internet informs and mobilises those who would otherwise be disinterested, underrepresented or unaware in the existing political system. Nevertheless, a more nuanced reading would reveal that serendipitous exposure to news of this nature alone would not be beneficial for political participation.

Despite the somewhat mixed responses about the mobilising and reinforcing effects of social news use, almost all perceived social news use as an empowering activity. As discussed earlier, one of the main motivations for consuming news on social media was to access a greater breadth of related information and perspectives. Accordingly, when talking about how social news use has benefited their involvement, several interviewees pointed out how the information gained, informed their activist work or cause. L. and S. in particular pointed out:

Yes, it has helped my work quite a lot...Because part of my work involves research and surveillance of policies. And so, it helps me keep up with some nuance changes in policies...Such news can be easily overlooked on print mainstream media.

It has increased my awareness of what needs to be done for the community in order for us to progress or at least have a better life. In Singapore, you don't even hear about social support groups for gay people or lesbians, and what more trans-people right? Social news has made me aware that there are a lot of trans-people committing self-harm because of family estrangement or not having friends or social support to get through the day.

The above-mentioned quotes require comment. First, the underlying assumption that news engagement shapes feelings of efficaciousness in participating in civic life is supported here. Indeed, the respondents believed that social news use, even in its most passive form, allowed them to discover new opportunities or problems related to their causes, which in turn helps them to carry out their respective activist roles. I caution, however, that the reported knowledge gained here is subjective rather than objective (Brucks, 1985) - the informants may be inclined to think they've become more informed about politics and current affairs than they really are.

While the significance of social news use in facilitating their own activist involvement was fully acknowledged by the informants, they were also not blind to its limitations or disadvantages. Nearly half of all participants voiced concerns of being potentially trapped in echo chambers. They cited previous instances where there was an incongruency between their expectations stemming 
from online discourses and what developed in reality - such as the 2015 General Elections - as an awakening to this phenomenon. Accordingly, many have since developed certain strategies to mitigate this, including deliberately sourcing for other media sources that is uncongenial to themselves or their causes. However, there is still some suspicion of how their news is filtered by algorithmic measures beyond their control. N., an active grassroots volunteer, after mentioning how diverse kinds of news can be obtained through information sorting tools on social media, added:

On one hand, it's helpful but on the other hand, it's scary. We don't exactly know how the algorithm works. It could be based on pure numbers. It could be based on intelligent word search. We don't know. Only Facebook would know exactly how it works. And at the end of the day, Facebook might want to monetise this, so there are a lot of question marks about algorithm-led news and tunnel vision.

Unsolicited attention from disingenuous individuals was named as another side effect of engaging in social news use. While most were willing to avail themselves to constructive debate on their primary social news platform, they expressed their annoyance with trolls - users who deliberately cause disruption by making baseless and derisive posts (Herring et al., 2002). The following quotes from F. and C. highlights how they were trolled:

So, there's the page that hasn't been updated for a long time but when it was active, it was very bizarre. It specifically seemed to specialise in screen capping social media accounts of people whom they identify as activists and then publishing these screencaps with very weird insinuations... when it's (sic) published, it's clearly not in good faith. For instance, they screen-capped my stuff about Detention without Trial and twisted it to say she's pro-terrorist.

I was harassed by the opposition trolls. They started stalking some of my posts. They don't privately message me but what they do is when you 'share' an article that is pro-government, they start to comment a lot of nonsense in there.

The primary concern over the presence of trolls is not so much the fear of being ridiculed, but the undermining of efforts to disseminate mobilising news and information. A related challenge facing many of the young activists was translating social news use activities of others into citizen participation, particularly in offline settings. R. admitted that compared to the content he produces on behalf of his organisation, interest and engagement in related offline events have been lacklustre. He rationalised:

It's difficult to convert people to want to actually do something. And that's when reality also hits most people. When social media is not the safe barrier anymore. Because now it's like, "Oh I'm actually going to be doing something. I'm actually going to be involved in something". A lot of people get more cautious with that.

While engaging disengaged peers is arguably a universal challenge for activists across the world, one contextual factor that makes this a more critical issue for these young activists is the perceived lack of responsiveness from government officials or authorities. As Q. noted:

I think this goes back to one of the questions just now - To what extent do you think people like myself can influence the government? So if you ask me on a scale of 1-10, I probably would rate it on a six or seven. Because it has happened before. But it's not direct influence. Because as far as most of the 
news sites I engage with are concerned, the government either doesn't acknowledge their existence or they think that they're illegitimate.

M. shared a similar sentiment when she stated her strategy in influencing the political process through a bottom-up approach:

For me it's not about what I say getting through to the policy makers. It's more of me trying to influence the people in my network. Because while I do have a lot of people on my social media who share a lot of my values, there are also a lot of people who don't.

Overall, despite the varied pathways into activism, all informants regarded social news use as an important means of continued political socialisation. They reported that engaging with news in socially networked spaces further stimulated their efficacy and awareness of politically salient issues and problems. A caveat in this finding however, is that there may be a discrepancy between their subjective and factual knowledge levels. In addition, potential obstacles preventing social news use from promoting citizen participation were also expressed. These ranged from homogeneity of views or opinions due to algorithmic measures, to trolls hindering opportunities of others to learn and participate in civic activities, to difficulty in drawing those who only engage in network-mediated news to be more involved in their specific causes. Overcoming the latter is seen as more effective in eventually influencing and affecting institutions of government than direct or online communication, including social news use.

\section{Discussion}

The aim of this article was to find out how young activists engage with social news, what influences these practices, and the implications these practices have on their own activist work. Consistent with Bennet's (2008) AC model, the young adults in this study expressed an inclination towards a variety of social media pages and digital outlets as news sources over traditional mass media. One possibility for this fragmented or "a la carte model of news gathering" (Marchi, 2012, p. 248 ) is that they find formal sources of news and information limited in terms of perspectives, which in turn prevents them from participating fruitfully in public affairs. As mentioned earlier, in Singapore, the internet, unlike mass media, is not as aggressively regulated and is consequently a host to a range of news outlets purveying both mainstream and alternative views. Nevertheless, it should also be pointed out that the present research suggests that usage does not necessarily equate to unequivocal trust in the medium. The activists were also generally cautious of news emanating from social media, understanding that its content can be highly subjective as well. However, they did not perceive this to be a serious problem. They were confident of, and preferred to, assemble and critique news-related content messages from both mainstream and alternative news sources on this channel. All in all, the way civically or politically engaged millennials engage with social media as sources of news and information in this study fits partially into Bennet's cross-generational DC to AC shift: while they're increasingly choosing to be informed through peer-shared information sustained by interactive information technologies, they are also dependent on mass media sources which have now established a presence on these spaces. The dyadic model of DC and AC may require contextualised adjustments. 
Sullivan (2000) and Feaster (2013) explicated information control as intrinsic to supporting positive face concerns and mitigating negative ones. The participants in this study continue to demonstrate support for this. Because of their sustained involvement in activism, many identified themselves as an authority on the topic of their respective causes and engaging in social news proactively was an opportunity to engage in related discourse. However, to better manage the often-contradictory expectations of a diverse network, they often consulted a range of both technical and social strategies. This practice of not simply relying on a platform's features to avoid unwanted audiences indicates that like their counterparts elsewhere (Vitak et al., 2015; Young \& Quan-Haase, 2013), Singaporean young adults are not necessarily disinclined towards technological privacy tools but are sceptical of its comprehensiveness. In an age where news engagement is becoming a significant component of overall social media activity, it behoves social media service providers to mitigate this. For a start, providers should implement more clear-cut procedures on how to activate various privacy management tools and articulate clearly in non-technical terms the range and implications of such features. This is particularly so for social networking sites such as Facebook, which offers a variety of granular privacy tools, such as friend groupings, item-level access controls, block lists, etc. By making privacy controls more consistent and user-friendly, social media service providers would encourage the adoption of such tools and alleviate users' sense of privacy breach. Consequently, social news users can be expected to be more confident in engaging in expressive forms of newsrelated activities because of this strengthened perception of information control.

The variance in responses regarding the mobilizing and reinforcing effects of social news use suggest that there are multiple socializing agents that provide young adults with the resources required for participating in public life. Indeed, as pointed out by Shah et al. (2009), other typical agents include family, school, media, and peers. However, while it is expected that most news consumers in the current media landscape receive news from a variety of sources, it should be emphasized that just reception alone to news media is not a precursor to active civic or political action. Often, regardless of how they first came to learn about the ways they could contribute to their communities meaningfully and effectively, the activists in this study were - and still are - active participants in the socialisation process themselves, engaging the information received with others through various mediated and non-mediated means, and thereby developing their knowledge and efficacy further. Accordingly, the findings in this research reaffirm earlier work that communicative behaviours are essential to an active citizenry and work in tandem with news consumption to promote citizen participation (Jung et al., 2011).

The findings of this study provide some insights as to how policymakers in Singapore can foster a more cohesive relationship with activists. First, our analysis shows that despite its disadvantages, young Singaporean activists regard social news use as integral to their citizenship. In other words, they accepted most of its risks because they believe these are dwarfed by the affordance of being able to receive and distribute information widely with minimal political intervention. Given that social news use may play an important role in revitalising civic and political participation in Singapore, it is crucial that the government continues to maintain this status quo as much as possible while addressing the challenges of the ever-changing digital media environment. The recent backlash against the controversial Protection from Online Falsehoods and Manipulation Act 2019 bill suggest that those who produce news-related content online are highly sceptical of its effectiveness 
in mitigating misinformation and perceive it as an encroachment on their freedom to dissent (Sim, 2020). For some, this bill might deter them from social news use altogether. Therefore, when it comes to implementing regulations concerning new media, the government should not shy away from soliciting public feedback. This has to be done effectively and regularly, rather than half-heartedly, with details of what has been taken into consideration and not communicated clearly to the public.

Moreover, the findings indicate a general sense of cynicism among our interviewees - the belief that the current system regards online grassroots voices as trivial. This undermines the efforts of the institutions and personnel currently involved in the government's efforts to improve communication between the state and its citizens. Accordingly, the existing policy decision-making structure can be further improved to include online discourses into its regular routines. This may include regularly interacting with citizens on its own pages, as well as with selected social news producers who have attracted a prominent following. Such a consultative or participatory approach, where citizens are given greater legitimacy in shaping policy discussions or providing feedback is likely to have a positive influence in their trust in the political system. The challenge of course is to figure out how to triangulate this with offline mechanisms so as to gain a more accurate assessment of public opinions.

All in all, this study adds new insights to the relationship between young activists' social news use and citizen participation. However, because the study employed purposive sampling, readers should exercise caution in interpreting findings. Given the traditionally low levels of political and civic activity among the electorate, the small, homogenous sample of highly engaged young adults limits the generalizability of findings. The findings of this study can be further corroborated with a national survey that uses a quota sample that more accurately captures a sample representative of Singapore's population. In addition, future qualitative studies should include focus groups involving young adults who are currently not regularly involved in any form of civic or political activity. The findings collectively would provide a more comprehensive picture of the opportunities and challenges of this media landscape for both state and civil society.

\section{References}

Bachmann, I., \& Gil de Zúñiga, H. (2013). News platform preference as a predictor of political and civic participation. Convergence: The International Journal of Research into New Media Technologies, 19(4), 496-512. https://doi.org/10.1177/1354856513493699

Bakshy, E., Messing, S., \& Adamic, L. A. (2015). Exposure to ideologically diverse news and opinion on Facebook. Science, 348(6239), 1130-1132. https:// doi.org/10.1126/science.aaa1160

Bennett, W. L. (2005, September). Civic learning in changing democracies: Challenges for citizenship and civic education. American Political Science Association, Washington, D.C.

Bennett, W. L. (2008). Changing citizenship in the digital age. In W. L. Bennett (Ed.), Civic life online: Learning how digital media can engage youth (pp. 1-24). MIT Press.

Bergström, A., \& Belfrage, M. J. (2018). News in social media. Digital Journalism, 6(5), 583-598. https:// doi.org/10.1080/21670811.2018.1423625 
boyd, danah. (2010). Social network sites as networked publics: Affordances, dynamics, and implications. In Z. Papacharissi (Ed.), A networked self: Identity, community, and culture on social network sites (pp. 39-58). Routledge; Scopus.

Brucks, M. (1985). The effects of product class knowledge on information search behavior. Journal of Consumer Research, 12(1), 1-16.

Cabrera, N. L., Matias, C. E., \& Montoya, R. (2017). Activism or slacktivism? The potential and pitfalls of social media in contemporary student activism. Journal of Diversity in Higher Education, 10(4), 400-415. https://doi.org/10.1037/dhe0000061

Cenite, M., Yee, C. S., Juan, H. T., Qin, L. L., \& Lin, T. X. (2008). Perpetual development journalism? Balance and framing in the 2006 Singapore election coverage. Asian Journal of Communication, 18(3), 280-295. https://doi.org/10.1080/01292980802239416

Chen, G. M., Pain, P., \& Barner, B. (2018). “Hashtag Feminism”: Activism or Slacktivism? In D. Harp, J. Loke, \& I. Bachmann (Eds.), Feminist Approaches to Media Theory and Research (pp. 197-218). Springer International Publishing. https://doi.org/10.1007/978-3-319-90838-0_14

Choi, J. (2016). Why do people use news differently on SNSs? An investigation of the role of motivations, media repertoires, and technology cluster on citizens' news-related activities. Computers in Human Behavior, 54, 249 256. https://doi.org/10.1016/j.chb.2015.08.006

Conway, M. M. (1985). Political participation in the United States. Congressional Quarterly.

Dalton, R. J. (2008). Citizenship norms and the expansion of political participation. Political Studies, 56(1), 76-98. https://doi.org/10.1111/j.1467-9248.2007.00718.x

Economist Intelligence Unit. (2019). Democracy index 2018: Me too? Political participation, protest and democracy. Retrived July 21, 2021, from https:/ /275rzy1ul4252pt1hv2dqyuf-wpengine.netdnassl.com/wp-content/uploads/2019/01/Democracy_Index_2018.pdf

Feaster, J. C. (2010). Expanding the impression management model of communication channels: An information control scale. Journal of Computer-Mediated Communication, 16(1), 115-138. https://doi.org/10.1111/j.1083-6101.2010.01535.x

Feaster, J. C. (2013). Great expectations: The association between media-afforded information control and desirable social outcomes. Communication Quarterly, 61(2), 172-194.

https://doi.org/10.1080/01463373.2012.751434

George, C., Hao, X., \& Wen, N. (2014). Social media and political participation in Singapore. In L. Wilnat \& A. Aw (Eds.), Social media, culture and politics in Asia (pp. 168-188). Peter Lang.

George, C., \& Raman, R. (2008). When big media meet 'we' media in Singapore. Australian Journalism Review, 30(2), 61-73.

Gill, H., \& Rojas, H. (2021). Communication Mediation Model Predicting Political Participation among Instant Messaging App Users: An OSROR Approach. Communication Studies, 0(0), 1-23.

https://doi.org/10.1080/10510974.2021.1899008 
Glynn, C. J., Huge, M. E., \& Hoffman, L. H. (2012). All the news that's fit to post: A profile of news use on social networking sites. Computers in Human Behavior, 28(1), 113-119. https://doi.org/10.1016/j.chb.2011.08.017

Goffman, E. (1959). The presentation of self in everyday life. Doubleday Anchor Books.

Hermida, A. (2011). Fluid spaces, fluid journalism: The role of the "active recipient" in participatory journalism. In J. Singer, A. Hermida, \& D. Domingo (Eds.), Participatory journalism: Guarding open gates at online newspapers. (pp. 177-191). John Wiley \& Sons.

Hermida, A., Fletcher, F., Korell, D., \& Logan, D. (2012). Share, like, recommend. Journalism Studies, 13(5-6), 815-824. https://doi.org/10.1080/1461670X.2012.664430

Herring, S., Job-Sluder, K., Scheckler, R., \& Barab, S. (2002). Searching for safety online: Managing 'trolling' in a feminist forum. Information Society, 18(5), 371-384. https://doi.org/10.1080/01972240290108186

Hogan, B. (2010). The presentation of self in the age of social media: Distinguishing performances and exhibitions online. Bulletin of Science, Technology \& Society, 30(6), 377-386. https://doi.org/10.1177/0270467610385893

Infocomm Media Development Authority. (2017). Fact Sheet-Online news sites to be placed on a more consistent licensing framework as traditional news platforms. Base. Retrived July 21, 2021, from https://www.imda.gov.sg/news-and-events/Media-Room/archived/mda/Media-Releases/2013/fact-sheet--online-news-sites-to-be-placed-on-a-more-consistent-licensing-framework-astraditional-news-platforms

Infocomm Media Development Authority. (2018). Annual survey on infocomm usage in households and by individuals for 2018. Retrived July 21, 2021, from https://www.imda.gov.sg/-/media/Imda/Files/Industry-Development/Fact-and-Figures/Infocomm-usage-HI/ Annual-Survey-on-Infocomm-Usage-byHouseholds-and-Individuals-Report-2018.pdf

Jung, N., Kim, Y., \& Gil de Zúñiga, H. (2011). The mediating role of knowledge and efficacy in the effects of communication on political participation. Mass Communication and Society, 14(4), 407-430. https://doi.org/10.1080/15205436.2010.496135

Kang, N., \& Kwak, N. (2003). A multilevel approach to civic participation: Individual length of residence, neighborhood residential stability, and their interactive effects with media use. Communication Research, 30(1), 80106. https://doi.org/10.1177/0093650202239028

Kemp, S. (2020). Digital 2020: Global digital overview. Retrived July 21, 2021, from https:/ / wearesocial.com/digital-2020

Kim, Y., Chen, H.-T., \& Gil de Zúñiga, H. (2013). Stumbling upon news on the Internet: Effects of incidental news exposure and relative entertainment use on political engagement. Computers in Human Behavior, 29(6), 2607-2614. https://doi.org/10.1016/j.chb.2013.06.005

Kluver, R. (2004). Political culture and information technology in the 2001 Singapore General Election. Political Communication, 21(4), 435-458. https:// doi.org/10.1080/10584600490518333

Kümpel, A. S. (2020). The Matthew Effect in social media news use: Assessing inequalities in news exposure and news engagement on social network sites (SNS). Journalism, 21(8), 1083-1098.

https://doi.org/10.1177/1464884920915374 
Kuo, F.-Y., Tseng, C.-Y., Tseng, F.-C., \& Lin, Cathy. S. (2013). A study of social information control affordances and gender difference in Facebook self-presentation. Cyberpsychology, Behavior, and Social Networking, 16(9), 635-644. https:// doi.org/10.1089/cyber.2012.0345

Kwon, K. H., Shao, C., \& Nah, S. (2021). Localized social media and civic life: Motivations, trust, and civic participation in local community contexts. Journal of Information Technology \& Politics, 18(1), 55-69. https://doi.org/10.1080/19331681.2020.1805086

Lang, C., \& Barton, H. (2015). Just untag it: Exploring the management of undesirable Facebook photos. Computers in Human Behavior, 43, 147-155. https://doi.org/10.1016/j.chb.2014.10.051

Lee, C. S., \& Ma, L. (2011). News sharing in social media: The effect of gratifications and prior experience. Computers in Human Behavior, 28(2), 331-339. https://doi.org/10.1016/j.chb.2011.10.002

Marchi, R. (2012). With Facebook, blogs, and fake news, teens reject journalistic "objectivity". Journal of Communication Inquiry, 36(3), 246-262. https:// doi.org/10.1177/0196859912458700

Marder, B., Joinson, A., \& Shankar, A. (2012). Every post you make, every pic you take, I'll be watching you: Behind social spheres on Facebook. Proceedings of the 45th Hawaii International Conference on System Sciences, 858-868. https://doi.org/10.1109/HICSS.2012.12

Marwick, A. E., \& boyd, danah. (2011). I tweet honestly, I tweet passionately: Twitter users, context collapse, and the imagined audience. New Media \& Society, 13(1), 114-133. https://doi.org/10.1177/1461444810365313

Mcleod, J. M., Scheufele, D. A., Moy, P., Horowitz, E. M., Holbert, R. L., Zhang, W., Zubric, S., \& Zubric, J. (1999). Understanding deliberation: The effects of discussion networks on participation in a public forum. Communication Research, 26(6), 743-774. https://doi.org/10.1177/009365099026006005

Mehdizadeh, S. (2010). Self-presentation 2.0: Narcissism and self-esteem on Facebook. Cyberpsychology, Behavior and Social Networking, 13(4), 357-364. https://doi.org/10.1089/cyber.2009.0257

Nah, S., Kwon, H. K., Liu, W., \& McNealy, J. E. (2021). Communication Infrastructure, Social Media, and Civic Participation across Geographically Diverse Communities in the United States. Communication Studies, $0(0)$, 1-19. https://doi.org/10.1080/10510974.2021.1876129

Nam, T. (2012). Dual effects of the internet on political activism: Reinforcing and mobilizing. Government Information Quarterly, 29(1), S90-S97. https://doi.org/10.1016/j.giq.2011.08.010

Newman, N., Fletcher, R., Kalogeropoulos, A., \& Nielsen, R. K. (2019). Reuters Institute Digital News Report 2019. Reuters Institute for the Study of Journalism. Retrived July 21, 2021, from https:/ / reutersinstitute.politics.ox.ac.uk/sites/default/files/2019-06/DNR_2019_FINAL_0.pdf

Ng, H. (2018). 4 in 5 Singaporeans confident in spotting fake news but 90 per cent wrong when put to the test: Survey. The Straits Times. Retrived July 21, 2021, from https:/ / www.straitstimes.com/singapore/4-in-5-singaporeans-confident-in-spotting-fake-news-but-90-per-cent-wrong-when-put-to-the

Norris, P. (2001). Digital divide: Civic engagement, information poverty, and the Internet worldwide. Cambridge University Press.

O'Sullivan, P. B. (2000). What you don't know won't hurt me: Impression management functions of communication channels in relationships. Human Communication Research, 26(3), 403-431.

https://doi.org/10.1093/hcr/26.3.403 
Park, C. S., \& Kaye, B. K. (2019). Mediating roles of news curation and news elaboration in the relationship between social media use for news and political knowledge. Journal of Broadcasting \& Electronic Media, 63(3), 455473. https:// doi.org/10.1080/08838151.2019.1653070

Saldana, J. (2015). The coding manual for qualitative researchers (3rd edition). SAGE Publications Ltd.

Saldaña, M., Mcgregor, S. C., \& Gil de Zúñiga, H. (2015). Social media as a public space for politics: Cross-national comparison of news consumption and participatory behaviors in the United States and the United Kingdom. International Journal of Communication, 9, 3304-3326.

Shah, D. V., McLeod, J. M., \& Lee, N. (2009). Communication competence as a foundation for civic competence: Processes of socialization into citizenship. Political Communication, 26(1), 102-117. https://doi.org/10.1080/10584600802710384

Shearer, E., \& Matsa, K. E. (2018). News use across social media platforms 2018. Pew Research Center's Journalism Project. Retrived July 21, 2021, from https:// www.journalism.org/2018/09/10/news-useacross-social-media-platforms-2018/

Sim, D. (2020). Singapore: It's a coincidence that fake news law has hit politicians. South China Morning Post. Retrived July 21, 2021, from https://www.scmp.com/week-asia/politics/article/3044888/singapore-defends-fake-news-law-saying-its-coincidence

Skoric, M. M., \& Poor, N. (2013). Youth engagement in Singapore: The interplay of social and traditional media. Journal of Broadcasting \& Electronic Media, 57(2), 187-204.

https://doi.org/10.1080/08838151.2013.787076

Smock, A. (2010). Self-presentation on Facebook: Managing content created by the user and others. Annual meeting of the International Communication Association, Suntec Singapore International Convention \& Exhibition Centre, Singapore. http://citation.allacademic.com/meta/p405056_index.html

Sveningsson, M. (2015). "It's only a pastime, really": Young people's experiences of social media as a source of news about public affairs. Social Media + Society, 1(2), 1-11. https://doi.org/10.1177/2056305115604855

Tai, K.-T., Porumbescu, G., \& Shon, J. (2020). Can e-participation stimulate offline citizen participation: An empirical test with practical implications. Public Management Review, 22(2), 278-296.

https://doi.org/10.1080/14719037.2019.1584233

Tsfati, Y., \& Cappella, J. N. (2003). Do people watch what they do not trust?: Exploring the association between news media skepticism and exposure. Communication Research, 30(5), 504-529.

https://doi.org/10.1177/0093650203253371

Verba, S., Schlozman, K. L., \& Brady, H. E. (1995). Voice and equality: Civic voluntarism in American politics. Harvard University Press.

Vissers, S., \& Stolle, D. (2014). The Internet and new modes of political participation: Online versus offline participation. Information, Communication \& Society, 17(8), 937-955.

https://doi.org/10.1080/1369118X.2013.867356

Vitak, J., Blasiola, S., Patil, S., \& Litt, E. (2015). Balancing audience and privacy tensions on social network sites: Strategies of highly engaged users. International Journal of Communication, 9(0), 1485-1504. 
Welsh, B. (2016). Clientelism and control: PAP's fight for safety in GE2015. The Round Table, 105(2), $119-128$. https://doi.org/10.1080/00358533.2016.1154390

Wohn, D. Y., \& Bowe, B. J. (2016). Micro agenda setters: The effect of social media on young adults' exposure to and attitude toward news. Social Media + Society, 2(1), 1-12. https://doi.org/10.1177/2056305115626750

Yamamoto, M., \& Morey, A. C. (2019). Incidental news exposure on social media: A campaign communication mediation approach. Social Media + Society, 5(2), 1-12. https://doi.org/10.1177/2056305119843619

Young, A. L., \& Quan-Haase, A. (2013). Privacy Protection Strategies on Facebook. Information, Communication \& Society, 16(4), 479-500. https:/ / doi.org/10.1080/1369118X.2013.777757

Young, K. (2009). Online social networking: An Australian perspective. International Journal of Emerging Technologies and Society, 7(1), 39-57.

Zukin, C., Keeter, S., Andolina, M., Jenkins, K., \& Delli Carpini, M. X. (2006). A new engagement? Political participation, civic life, and the changing American citizen. Oxford University Press.

\section{Appendix A}

1. On average, which of the following social media applications do you access most often?

\begin{tabular}{|l|l|}
\hline Application & $\begin{array}{l}\text { Rank in order of frequency } \\
1=\text { most frequent } \\
6=\text { least frequent }\end{array}$ \\
\hline Facebook & \\
\hline Instagram & \\
\hline Twitter & \\
\hline Google+ & \\
\hline YouTube & \\
\hline WhatsApp & \\
\hline $\begin{array}{l}\text { Other } \\
\text { (please } \\
\text { specify) }:\end{array}$ & \\
\hline
\end{tabular}

2. Approximately how long have you had an account on the application that you use most frequently? years.

3. Typically, which of the following social media applications do you use for social news use most often?

\begin{tabular}{|l|l|}
\hline \multirow{2}{*}{ Application } & $\begin{array}{l}\text { Rank in order of frequency } \\
1=\text { most frequent } \\
6=\text { least frequent }\end{array}$ \\
\hline
\end{tabular}




\begin{tabular}{|l|l|}
\hline Facebook & \\
\hline Instagram & \\
\hline Twitter & \\
\hline Google+ & \\
\hline YouTube & \\
\hline WhatsApp & \\
\hline $\begin{array}{l}\text { Other } \\
\text { (please } \\
\text { specify) : }\end{array}$ & \\
\hline
\end{tabular}

4. On a typical week, how much time on average do you consume news on the following media channels?

\begin{tabular}{|c|c|c|c|c|c|c|c|}
\hline & Never & $\begin{array}{l}\text { Less than } \\
\text { once a week }\end{array}$ & $\begin{array}{l}\text { Once a } \\
\text { week }\end{array}$ & $\begin{array}{l}2-3 \\
\text { times } \\
\text { a } \\
\text { week }\end{array}$ & $\begin{array}{l}4-6 \\
\text { times } \\
\text { a } \\
\text { week }\end{array}$ & $\begin{array}{l}\text { Once } \\
\text { a day }\end{array}$ & $\begin{array}{l}\text { Several } \\
\text { times a } \\
\text { day }\end{array}$ \\
\hline Television & & & & & & & \\
\hline Radio & & & & & & & \\
\hline Newspaper & & & & & & & \\
\hline Social media & & & & & & & \\
\hline $\begin{array}{l}\text { Internet (over- } \\
\text { all) }\end{array}$ & & & & & & & \\
\hline
\end{tabular}

5. How often do you engage in a conversation about politics or current affairs with others?

\begin{tabular}{|l|l|}
\hline Frequency & Tick appropriately \\
\hline Never & \\
\hline Less than once a week & \\
\hline Once a week & \\
\hline 2-3 times a week & \\
\hline
\end{tabular}




\begin{tabular}{|l|l|}
\hline 4-6 times a week & \\
\hline Once a day & \\
\hline Several times a day & \\
\hline
\end{tabular}

6. How would you describe your level of attention to news pertaining to local politics or social issues?

\begin{tabular}{|l|l|}
\hline Level of interest & Tick appropriately \\
\hline None & \\
\hline Little attention & \\
\hline $\begin{array}{l}\text { A moderate amount of atten- } \\
\text { tion }\end{array}$ & \\
\hline Close attention & \\
\hline Very close attention & \\
\hline
\end{tabular}

7. How would you describe your level of interest in local politics or social issues?

\begin{tabular}{|l|l|}
\hline Level of interest & Tick appropriately \\
\hline Not at all interested & \\
\hline Not very interested & \\
\hline Neutral & \\
\hline Somewhat interested & \\
\hline Very interested & \\
\hline
\end{tabular}

8. To what extend do you agree with the following statement: "I think people like me can influence government."

\begin{tabular}{|l|l|}
\hline Level of agreement & Tick appropriately \\
\hline Strongly disagree & \\
\hline Disagree & \\
\hline Somewhat disagree & \\
\hline Neither agree or disagree & \\
\hline Somewhat agree & \\
\hline
\end{tabular}




\begin{tabular}{|l|l|}
\hline Agree & \\
\hline Strongly agree & \\
\hline
\end{tabular}

Age:

Sex (circle): Female / Male

Highest education achieved:

Ethnicity:

\section{Appendix B}

1) You mentioned that that you usually use (refer to response on Q.3 in pre-interview survey) for social news use. Please elaborate why this is your preferred social media platform compared to others.

2) Who do you communicate or interact with mostly when participating in social news use? Why?

3) What local news on politics, economy or social issues have you responded to actively when consuming news on social media? Why?

4) Unlike traditional mass media in Singapore, the Internet is home to a wider spectrum of socipolitcal news and information. How do you negotiate these different sources of information?

5) If your views were different from those expressed by the majority on the social media news page that you frequent, how would you respond?

6) Do you think you will be less involved or interested in civic or political issues if social media as a news source did not exist? Why or why not?

7) How has social news use affected your participation or work in activism?

8) Do you think engaging in social news use helps you participate in the national policy-making process? How so or how not?

9) While the government has employed a "soft touch" approach towards regulating the Internet, legal restrictions on expression remain in place. How has this restriction influence your social news use behaviour?

10) What are the major drawbacks from participating in social news use? 


\section{About the Author}

\section{Winston Teo}

Winston Teo recently completed his PhD at the University of Auckland. His research interests include computer-mediated communication, social media, digital activism, young people, and effects of new media on well-being. He has been working with and for a number of government agencies, academic institutions, and independent research centres. 